\title{
Serial crowdfunding in start-up development: a business network view
}

\author{
Fulvio Fortezza \\ Department of Economics and Management, University of Ferrara, Ferrara, Italy, and \\ Alessandro Pagano and Roberta Bocconcelli \\ Department of Economics, Society, and Politics, University of Urbino Carlo Bo, Urbino, Italy
}

\begin{abstract}
Purpose - Even though the crowdfunding (CF) literature is rapidly reaching its maturity phase, the topic of serial CF (i.e. the participation in more than one CF campaign) is as much promising as still largely under explored. This study thus aims to offer a thorough view of the dynamic and complex processes characterizing the participation of the start-ups to more than one campaign adopting a business network perspective.

Design/methodology/approach - In line with an explorative research aim, a multiple case study analysis is performed by taking into consideration four start-ups engaged in more than one CF campaigns with different combinations of equity and non-equity CF, adopting the actor-resourceactivity (ARA) model as theoretical framework.

Findings - Multiple CF campaigns are embedded in the overall changing startup's network and are affected by the concurrent and overlapping startup's development processes. From this standpoint, the adoption of the ARA model suggests to reconsider the "serial" dimension of multiple CF campaigns. These processes can be more or less "linear" as they could be affected by the combination of CF schemes and by the degree of alignment of actors, activities and resources, whose "assembly" can be facilitated by learning processes and impaired by unexpected circumstances. Originality/value - This paper explores in depth the startup's serial CF journey, building on recent studies calling for stronger analyses of the directions and outcomes of innovative funding trajectories pursued and implemented by new business ventures. From this standpoint, to the best of the authors' knowledge, this is the first study to consider a complete spectrum of combinations between CF schemes within serial CF, thus allowing for a better understanding of the role of such a factor within a dynamic and contextual view, that is, that offered by the business network perspective. This paper also contributes to the Industrial Marketing and Purchasing research on start-ups.
\end{abstract}

Keywords Start-ups, Business network, Serial crowdfunding, ARA model

Paper type Research paper

\section{Introduction}

Crowdfunding (hereafter, CF) platforms represent a new font of resources to support entrepreneurial projects. CF has risen dramatically in the past few years and is expected to continue to grow up to $\$ 300$ bn in cumulative transactions by 2025 (Barbi and Mattioli, 2019). It consists of an open call for the provision of financial resources, either in the form of donations or in exchange for non-financial rewards or financial gains to support specific initiatives (Belleflamme et al., 2014). The most widespread CF schemes are the non-equity reward-based CF (NECF) ones, where the funders' reward is the future product, and the equity-based CF (ECF) ones, where funders get a real capital share.

CF has received increasing attention by scholars who mostly focused on understanding its specific features (Raab et al., 2020), the main factors affecting the participation of both proposing and supporting actors (Groza et al., 2020) and its campaign success (Mamonov and Malaga, 2019). Currently,

The current issue and full text archive of this journal is available on Emerald Insight at: https://www.emerald.com/insight/0885-8624.htm

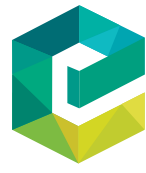

Journal of Business \& Industrial Marketing 36/13 (2021) 250-262

Emerald Publishing Limited [ISSN 0885-8624] [DOI 10.1108/JBIM-05-2020-0243]
$\mathrm{CF}$ is no longer seen only as a financial tool; rather, it is often conceived as a new way to enter the market and compete (Viotto Da Cruz, 2018) and to gain access to a variety of resources through one or more CF campaigns (Pollack et al., 2019).

From this standpoint, the stream of literature on "serial CF," namely, the participation in more than one CF campaign, is gaining growing attention from scholars (Stanko and Henard, 2016; Butticè et al., 2017; Bessière et al., 2019), as it fosters a better understanding of the relevance of CF projects in the development processes of start-ups (Paschen, 2017). However promising this topic appears, it remains still largely underexplored; the few existing studies devoted to it (Butticè et al., 2017; Skirnevskiy et al., 2017; Lee and Chiravuri, 2019) adopt a quite narrow perspective on the phenomenon, with

(C) Fulvio Fortezza, Alessandro Pagano and Roberta Bocconcelli. Published by Emerald Publishing Limited. This article is published under the Creative Commons Attribution (CC BY 4.0) licence. Anyone may reproduce, distribute, translate and create derivative works of this article (for both commercial and non-commercial purposes), subject to full attribution to the original publication and authors. The full terms of this licence maybe seen at http://creativecommons.org/licences/by/4.0/legalcode

Received 16 May 2020

Revised 11 December 2020

6 May 2021

29 July 2021

Accepted 16 September 2021 
scant attention placed on its actual processes (Bessière et al., 2019).

In light of this, the aim of this paper is to analyze more in depth the participation of a start-up in multiple CF projects by taking into account the role of CF typology (Paschen, 2017; Pollack et al., 2019) by exploring and comparing different combinations of the most frequently used CF schemes (i.e. NECF and ECF); and adopting a wider and more dynamic perspective of the journey undertaken by start-up firms taking part in multiple CF campaigns.

Thus, the paper aims to answer the following research question (RQ):

RQ1. How do start-up firms participate in multiple $\mathrm{CF}$ projects?

Addressing this RQ helps gain a better understanding of how multiple CF campaigns function, thus contributing to the entrepreneurship field in relation to the call by Shephard (2015) for a more in-depth understanding of the role of microprocesses in the development of start-ups.

We argue that the RQ can be effectively addressed adopting the actor-resource-activity (ARA) framework developed within the business network approach proposed in the Industrial Marketing and Purchasing (IMP) group. The IMP perspective has been used in the analysis of start-up evolution and development (Aaboen et al., 2017; Baraldi et al., 2019) and, recently, of CF networks (Brown et al., 2018), because of its emphasis on networks, business interaction, and resource development (Håkansson et al., 2009). The ARA framework highlights the role of actors - as interconnected nodes in the network, with their own identity - activities - as they are implemented by actors - and resources - as they are activated and combined in an interdependent manner. ARA has already been used in recent studies to delve into start-up processes (Cantù et al., 2018; Petrucci, 2018; Pagano et al., 2018). Therefore, the present study also contributes to strengthening the connection between the IMP approach and the entrepreneurship field (Baraldi et al., 2019), with regard to the role of contexts and of multiple networks consisting of different actors and displaying different logic.

The research methodology is based on qualitative, multiple case study analysis (Eisenhardt, 1989; Yin, 2011) adopting a processual perspective, in light of the explorative nature of the $\mathrm{RQ}$ and in line with recent studies addressing the complexity of start-up financing and involvement in CF campaigns (Bessière et al., 2019; Pollack et al., 2019). The empirical analysis concerns four case studies of start-ups engaged in more than one $\mathrm{CF}$ project with different combinations and sequences of $\mathrm{ECF}$ and NECF.

The paper is structured as follows. Section 2 offers the theoretical background of the analysis; the extant literature on the key aspects of CF in business start-up development is reviewed, and the business network perspective and the ARA framework are discussed to provide the conceptual lenses for analyzing start-up development and serial CF. Section 3 addresses the research methodology and Section 4 is devoted to the case analysis. In Section 5, the findings are discussed relative to the $R Q$, in line with the three layers of the ARA framework. Section 6 outlines the main contributions of the research both at the theoretical and managerial level. Section 7 addresses the main limitations of the study and points to future research lines.

\section{Background literature}

2.1 Key aspects of crowdfunding in start-up processes $\mathrm{CF}$ is described as a multifaceted phenomenon (Lagazio and Querci, 2018) for two main reasons. First, it is a hybrid practice, as it involves both economic and social aspects (André et al., 2017). Second, there are different forms of CF, even though they are all based on a peer-to-peer dimension (Bruton et al., 2015).

In the following subsections, we focus on three key issues of CF used in the process of starting up a new business.

2.1.1 Crowdfunding schemes: non-equity reward-based crowdfunding and equity crowdfunding

Existing studies on CF mainly concern the NECF and the ECF. The main difference between the two lies in the primary goals of the parties involved in the exchange and in the kind of reward earned by the backers (Mollick, 2014). In fact, ECF tends to create an entrepreneur-investor relationship, whereas in NECF schemes, backers act as consumers seeking novelties, opportunities or other intangible rewards.

Initially conceived as a smart way to test and develop a burgeoning product idea, NECF rapidly became a marketing tool (Brown et al., 2017), so much so that now, scholars strongly agree that the overall benefit of using NECF goes well beyond fundraising (Roma et al., 2017). It might include market testing, promotion, market access and product distribution (Butticè et al., 2017; Viotto Da Cruz, 2018), which means that NECF can influence marketing decisions, making them more effective (Hu et al., 2015).

Thus far, ECF has been mainly considered an important financial option for start-ups, especially for established or "ready" start-up ventures (Belleflamme et al., 2014; Paschen, 2017). In fact, ECF can provide large amounts of money without crowding out or replacing traditional-equity investors such as venture capitalists and business angels (Kaminski et al., 2019). However, scholars are increasingly pointing to the opportunities it offers in marketing terms as well (Eldridge et al., 2021; Di Pietro et al., 2018). These benefits stem from the interactions with backers who are different from those involved in NECF (e.g. entrepreneurs, potential users, specialists in finance and marketing); additional factors include the different CF platforms and related mechanisms where such interactions occur (Brown et al., 2019).

\subsubsection{Role of relationships}

In both NECF and ECF, benefits are strictly related to the relationships with the crowd (Nielsen, 2018). Consistent with its sharing-based nature, CF is characterized by open and evolving networks (Lehner et al., 2015; Brown et al., 2019) marked by "fluid memberships" and no formal inclusion or exclusion criteria (Fehrer and Nenonen, 2020).

Project proponents should be able to proactively exploit the crowd (Brown et al., 2018) by showing a strong openness to "learning and unlearning" (Pollack et al., 2019), but also the willingness to somehow give agency to the crowd.

CF scholars mostly refer to the concept of "social capital" when describing relationships in CF (Mollick, 2014). Early 
research on this topic was about the power of the "external social capital," represented by the close networks created by the project proponent's family and friends (Ordanini et al., 2011). Subsequently, scholars shifted their attention to the opportunities provided by the "internal social capital" (Eiteneyer et al., 2019), which comes from a deep interconnection between project proponents and backers throughout the CF journey within a given CF platform.

In sum, there is increasing attention in literature to the "network dimension" of CF and to the comprehensive and dynamic relationships with a multiplicity of actors. These relationships, which arise around one or more CF campaigns, play a crucial role in mobilizing different sources of funding, compensating for the scarcity of resources inherent in being a start-up.

\subsection{3 "Seriality" in crowdfunding}

While the phenomenon of serial CF is gaining increasing relevance as it is perceived as a more stable source of resources (Bessière et al., 2019; Skirnevskiy et al., 2017), the current literature still reveals the lack of an in-depth understanding of serial CF's main patterns.

The few existing studies on this topic are mostly focused on a type of seriality that can be called "linear," which develops within an NECF scheme and within the boundaries of a given CF platform (e.g. Kickstarter or Indiegogo). In this sense, scholars (Butticè et al., 2017; Lee and Chiravuri, 2019; Skirnevskiy et al., 2017) highlight how a proactive use of serial CF can lead project proponents to an ever better performance by means of relationships and learning. These studies specifically underscore that the most loyal and active backers trigger a comprehensive reinforcing mechanism for the $\mathrm{CF}$ campaigns launched over time. Moreover, the role of relationships is often emphasized in terms of the mutual support, trust and reciprocity that exist among users on a given CF platform. This community-building pattern is specific to $\mathrm{CF}$ and makes serial CF something different from serial entrepreneurship (Lee and Chiravuri, 2019). Nevertheless, these studies acknowledge the role of relationships solely within the boundaries of CF campaigns, with scant attention devoted to the wider set of relationships in which the start-up is concurrently involved.

The only study taking into account a combination of ECF and NECF is that proposed by Bessière et al. (2019). Here, the NECF campaign appears instrumental in shaping the entrepreneurial team's cognitive resources and capabilities, thus making the start-up ready for the subsequent equity investors. This process affected the company's development trajectory. The line of research - that could be labeled "hybrid CF" - outlined in this study merits further investigation to reach a comprehensive understanding of the participation processes in multiple CF campaigns.

\subsection{Start-up development and serial crowdfunding: a business network perspective}

Understanding the complex underlying processes of serial CF requires an appropriate conceptual framework. As shown by Brown et al. (2019), the business network perspective represents a valuable, network-based conceptual basis to investigate serial CF processes, in light of its "focus on interaction processes at the micro level" (Baraldi et al., 2019, p. 9). The business network approach was developed as an attempt to understand exchanges between firms, to learn how these interaction processes lead to the establishment of business relationships and the emergence of business networks in which firms are embedded (Håkansson et al., 2009; Håkansson and Snehota, 2017) and can pursue a stronger position, to be maintained through effective business networking (Ford and Mouzas, 2013).

Notably, the business network approach could shed light on serial CF processes for two main reasons. First, the IMP literature in recent years has spotlighted start-up development and its underlying processes (Aaboen et al., 2017; Baraldi et al., 2019; Baraldi et al., 2019), arguing that both in the beginning and in later development, each start-up process is interconnected with other relevant processes and activities concerning start-up development that involve other actors and networks. Start-ups might interact with a variety of business, that could be related to different development, production and user settings (Landqvist and Lind, 2019) and also with communities that share an interest or passion, thus simultaneously dealing with both business and social networks (Brown et al., 2018; Pagano et al., 2018). The exploitation of previous business relationships could facilitate the process of "strategizing" in a network context (Laari-Salmela et al., 2015), shaped by the building of a network identity that not only provides legitimization but is also able to attract customers, suppliers and supporting organizations (La Rocca et al., 2019; Laari-Salmela et al., 2019).

Second, an in-depth analysis of serial CF processes can be effectively based on the ARA framework (Håkansson and Snehota, 1995) previously adopted in recent studies on start-up processes (Cantù, 2018; Cantù et al., 2018; Petrucci, 2018; Pagano et al., 2018). The ARA framework highlights the deepening of relationships and network evolution by focusing on three connected layers: actors, as nodes in the network with their own identity; activities, as they are implemented by actors; resources, as they are activated and combined. The ARA framework is thus useful for a more in-depth examination of the variety of actors in CF campaigns and to analyze the type of activities required by the variety and complexity of CF schemes (Brown et al., 2019). Moreover, the ARA framework combines actors and activities with resources, which represent a key component in the development of start-up firms, as they are engaged in the "assembly" of resources (Ciabuschi et al., 2012) accessed through multiple CF campaigns. Start-ups often require various types of resources such as financing, marketing and technological competences, IT systems and technical facilities that might be available internally or externally (Bocconcelli et al., 2017; Landqvist and Lind, 2019).

Therefore, using the ARA framework can help deepen our understanding of the behavior of start-up firms in serial CF campaigns; these firms must deal with their "liability of newness" (Guercini and Milanesi, 2019; Baraldi et al., 2019) while engaged in CF-related activities (Brown et al., 2019). Adopting ARA to investigate multiple CF campaigns could contribute both to the emerging network-related research on CF (Brown et al., 2018) and to the recent effort to link the IMP approach and the field of entrepreneurship (Baraldi et al., 2019). 


\section{Research objectives and methodology}

The paper adopts a qualitative research methodology based on multiple case studies (Yin, 2003; Yin, 2011), because of the explorative nature of the RQ, aimed at disentangling the microprocesses relative to key resources, activities and actors that are activated when start-ups are involved in more than one $\mathrm{CF}$ campaign. This choice is in line with recent calls for more indepth qualitative research on start-ups and CF (Pollack et al., 2019; Bessière et al., 2019) and represents a methodology complementary to existing contributions on serial $\mathrm{CF}$ campaigns, which have mostly adopted a quantitative approach (Butticè et al., 2017). In fact, it has been argued that the analysis of multiple CF campaign participation can be more fruitfully conducted through a "qualitative process-based approach" (Bessière et al., 2019, p. 4), because it mainly concerns behavioral dimensions and changes occurring over time in multiple and concurrent interconnected aspects (i.e. actions, actors, resources and other sources of funding).

Notably, to enable a network perspective on our analysis, the ARA framework has been adopted as a conceptual and methodological foundation (Håkansson and Snehota, 1995). The ARA model has allowed us to explicitly focus on the establishment of resource ties, activity links and actor bonds in the evolution of CF campaigns, while linking the analysis of CF campaigns to the development of the start-up (Baraldi et al., 2019). This perspective has been applied to four cases of startups involved in multiple CF campaigns. The multiple case study methodology has been fruitfully adopted with regard to the evolutionary development of start-ups (Aaboen et al., 2012) and is useful for both in-depth case analysis and cross-case comparison (Eisenhardt, 1989).

Because we aim to investigate how start-ups participate in multiple CF projects with different types of CF schemes, the four cases were chosen to take into account the variety of combinations related to serial CF campaigns. All four cases were selected through purposeful sampling (Patton, 2001), on the basis of the following criteria and their relevance to the issue under investigation: active in tangible products; and engaged in different $\mathrm{CF}$ combinations in the first two campaigns (ECFECF, NECF-NECF, NECF-ECF, ECF-NECF) of their serial CF path.

The first criterion was adopted to guarantee homogeneity among selected cases and to take into consideration the additional complexities linked to production-related activities, as preliminary interviews with $\mathrm{CF}$ platform managers and experts had highlighted. The second criterion was chosen to allow comparability as well and with the aim of investigating possible combinations of CF schemes at the same "level of CF experience" for all the companies, regardless of the stage of maturity of the start-up. The analysis was thus conducted with a specific focus on the first two campaigns; however, additional data on the subsequent campaigns (if any) was also collected and analyzed.

In the first research phase, we conducted four interviews with experts in the field (three managers in the field of consultancy in CF campaigns and one country manager of a well-known international NECF platform). Concurrently, we had contacts with an Italian Facebook group of crowdfunders (made up of both backers and project proponents). Finally, we performed an in-depth review in the main specialized blogs and newspapers of the start-up world. This work allowed us to select an initial sample of eight start-ups worth investigating. In the second research phase, each of the companies was contacted for a preliminary short interview to test the reliability of information previously collected and verify their availability to take part in the research.

The selection process resulted in four start-ups - all based in Italy and engaged in high-tech tangible products - pursuing different CF scheme combinations (Table 1). Our primary two-pronged source of data (Table 1) consisted of direct semistructured interviews (eight in total) with key informants in the start-ups; and netnographic analysis.

The interviews were focused on the establishment and evolution of the start-up and on the first two CF projects, highlighting the differences and similarities between the two rounds. This revealed the critical changes that had occurred in terms of resources, activities and actors involved from the first experience to the next one. Moreover, during the interviews, additional information was collected on possible future, already planned or ongoing CF campaigns following the first two in our analysis. Interviews were planned for each company in a twostep approach (Table 1) and all of them were recorded and transcribed.

The second prong was netnography (Kozinets, 2002). In other words, for each of the start-up firms, we analyzed a number of codified content items (comments, replies, posts and communications) from different Web sources such as CF platforms, company blogs/websites and their social media platforms. In all of the cases, follow-up e-mails, phone calls and secondary data such as the companies' newspaper interviews, articles and press releases were used to complete our data collection and support the ex post reconstruction.

We then followed a systematic combining procedure, adopting an abductive approach (Dubois and Gadde, 2002) for the data analysis, given the explorative nature of case research based on a logic of investigation aimed at recursively matching theoretical approaches to the topic and empirical observations (La Rocca et al., 2017). Finally, we coded the analysis according to common themes concerning the role played by participation in multiple CF campaigns with different schemes in the development of start-ups, in an effort to link our empirical observations to theoretical knowledge. The cases were then placed in temporal phases following the two CF campaigns, thus taking into account the specificities of and the main factors shaping each of them (Quintens and Matthyssens, 2010).

\section{Empirical analysis}

\subsection{Alpha case}

Alpha was established in 2012 by Francesco, who invested his own personal savings, with the goal of designing and producing smart glasses for the $\mathrm{B} 2 \mathrm{C}$ market. With a background in economics and professional experience as a financial controller in large firms, Francesco attempted to develop the initial product idea by involving two share-holding technical collaborators/partners. One of the two owns a small firm that engineers and produces wearable technologies. In the same year, Alpha obtained a patent for the smart glasses. 


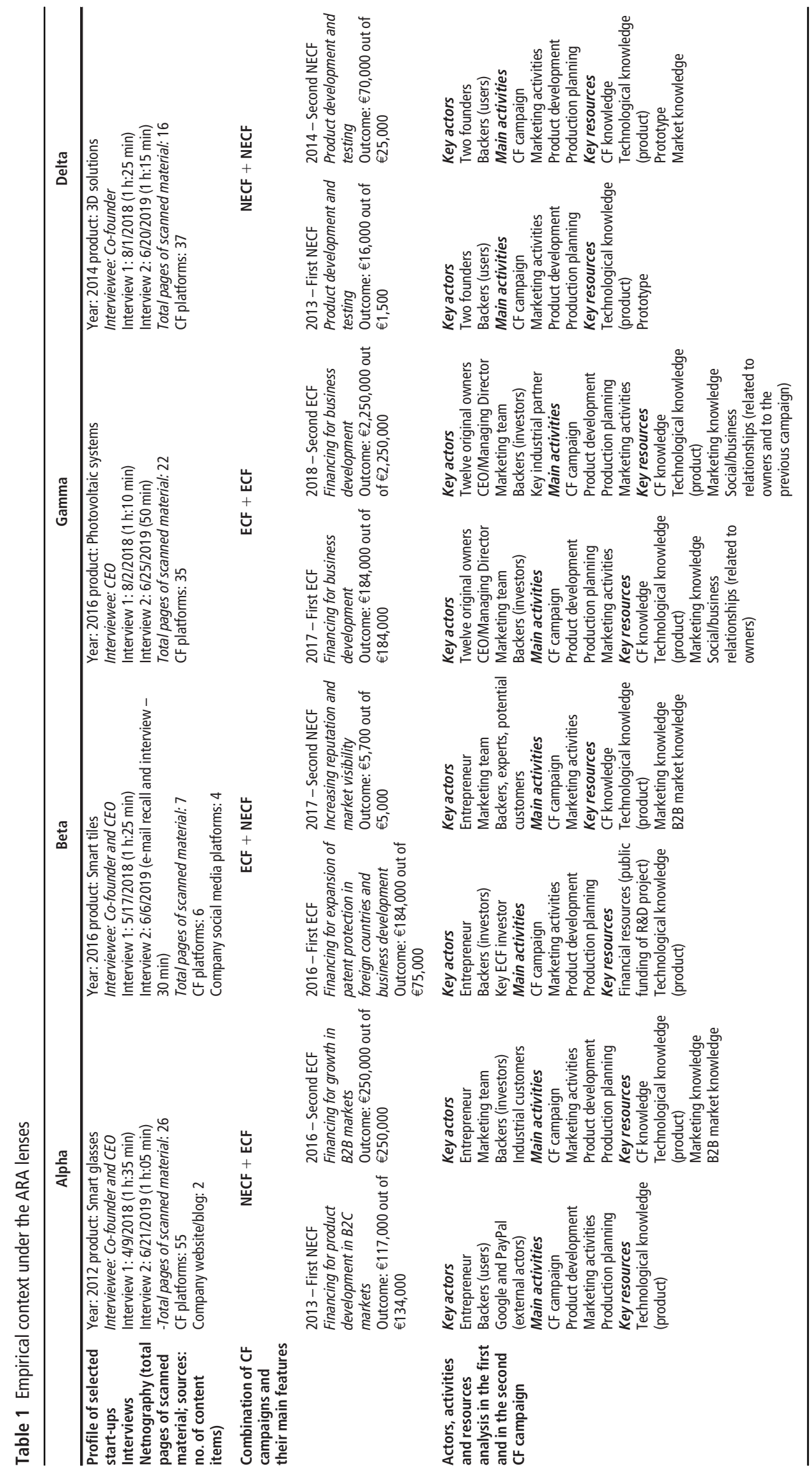


Aiming to translate the initial product idea into a prototype, Alpha launched an NECF campaign in 2013. Indiegogo was chosen because of its perceived softer requirements, compared to Kickstarter, and because it proposed its product as a backer's reward, forecasting production of 400 units. Because of limited knowledge about $\mathrm{CF}$ on the specific platform (i.e. how to manage texts and videos), the first campaign proved to be quite challenging for Alpha, which struggled to reach the set goal. The company managed all the activities internally and felt it received little support from the chosen platform.

However, some unexpected incidents occurred which ultimately helped the company. First, Google intimated Alpha not to use the chosen brand name because of its strong similarity to Google Glasses; then, PayPal claimed that the company could not take the money provided by backers because a real product did not exist yet. All this dramatically put Alpha in the spotlight, thus triggering the attention of the American media and consequently, boosting the CF campaign. In the end, Alpha was able to collect almost the entire amount of funding requested. Unfortunately, the production of smart glasses proved to be much more difficult than expected and none of the investors received their reward. The company was aware that being involved in a complex CF campaign can bring to light its weaknesses:

The big lesson here probably is that the hype cycle can change from sky-high to ground level. We have pioneered technologies that did not exist, and use cases that needed to be imagined. We have been able to fix the financial and technological issues, even better than we expected; and we thought the market risk was under control. Nevertheless we still need to work harder and harder (Alpha's CEO, netnography).

However, thanks to CF, Alpha was able to access new resources, in addition to the financial ones generated by the campaign, in the form of useful technical feedback on the product and on the market potential, brand visibility and distribution at the international level.

We now have a target market which would warmly appreciate our product, and this may help us find the resources we need to succeed (Alpha's CEO, netnography).

Overall, after this first campaign, Alpha is more aware of how CF really works, how complex it is and what it requires.

What's very clear to me now is that you cannot ask for money just to fund a rough idea. It's much better and much fairer if you already have at least a strong prototype and ask the backers to improve it (Alpha's CEO, interview).

In the two years that followed, the company obtained a first round of public funding to enhance the business and also received support from a business angel. As a result, Alpha strengthened its organization by hiring new employees in R\&D activities and finally came up with a technological demonstrator. In early 2016, the company changed its product strategy, turning to $\mathrm{B} 2 \mathrm{~B}$ markets, thus developing prototypes to be used by technical staff engaged in complex production and logistical processes in large firms.

Later in 2016, Alpha launched its second CF campaign (Table 1) based on an equity approach - because of the switch to $\mathrm{B} 2 \mathrm{~B}$ - with the platform Tip Ventures to boost its business. The platform was chosen because of its reputation in the B2B market. However, reaching the financial target took longer than expected, also because of the perceived limited support provided by the CF platform.
In this ECF campaign, the experience with backers was different from the NECF campaign, given Alpha's now acquired expertise and propensity to interact in a more continuous way. To provide support to the second campaign, Alpha decided to involve two young collaborators for marketing activities, mainly through social media and using LinkedIn as a key platform. Meanwhile, Alpha was also involved in a European R\&D Project on smart glasses in the sports sector; thus, the company was again active in the B2C market.

In 2018, Alpha launched a third CF campaign (again, equitybased) using the same platform and easily reaching its target, thanks to the knowledge gained by the company with regard to $\mathrm{CF}$ activities, a better planned marketing-related effort and the indirect endorsement offered by its well-known customers in the B2B market. In 2019, Alpha obtained new public funding for the creation of a special device with applications in the construction sector. It also plans to launch a new product suitable for several consumer applications through a new NECF campaign based on a pure pre-sale scheme.

\subsection{Beta case}

Beta was established by Alessio to design and produce smart tiles able to record data and generate/store energy. Alessio came up with the initial idea in 2012 when he wrote his university engineering degree thesis on sensors able to generate/store energy when subjected to pressure. In 2014, Alessio enhanced his project and involved two other electronic engineers with complementary technological knowledge who later became partners in the venture.

The initial search for financing was not successful and the team realized it needed to gain additional managerial and marketing skills to attract potential customers and investors. A key opportunity arose, thanks to their success in a regional start-up competition and their eight-month involvement in an incubator, which later partnered with the newly established company. At the end of this process, Alessio took the helm, managing the company and leaving the engineering activities in the hands of his collaborators. In 2016, Beta obtained a patent recognized in Italy, but then, the start-up needed new financial resources to expand the patent protection internationally and further develop its business, in two important ways.

On the one hand, Beta was able to exploit the financial support of public funding for two R\&D projects and, on the other hand, it launched its first ECF project on the BacktoWork24 platform. After a few investments by small backers and a slowdown in contributions, a significant investment by a professional backer boosted interest in the campaign so much that Beta collected more than double the target sum. This first CF project also increased Beta's visibility and reputation in the market (Table 1).

In 2017, Beta launched an NECF campaign on Eppela with the clear marketing goal to further strengthen the company's brand awareness and build significant business relationships.

I think that CF is the best way to promote a disruptive idea. Thanks to the networking opportunities fostered by a CF campaign you can create strong ties with multiple players coming from many different fields (Beta's CEO, netnography).

Eppela was chosen because of its support for small campaigns, based on the provision of half of the pursued target. This campaign was carefully planned for three months by preparing 
all the communication and promotion materials; organizing "physical" events to promote the campaign; selecting different types of rewards for investors; planning an effective press campaign to support the $\mathrm{CF}$ project; and launching social media communication activities. This second CF round was successful on two fronts: it achieved the financial targets, albeit limited and in this case of secondary importance, with a somewhat symbolic goal, and obtained satisfactory marketing results, thanks to the strong interest displayed by technical experts, opinion leaders, specialized press and potential customers, including large firms, that were reached through the platform's community.

In the future, Beta plans to launch both NECF and ECF campaigns to increase its brand visibility in foreign markets to attract potential partners - as investors - able to transfer key managerial resources and to gain access to additional financial resources for further investments.

\subsection{Gamma case}

Gamma was established in 2016 through an initial investment by 12 shareholders, including the Bicocca University of Milan, several medium-to-large high-tech companies and a management consulting agency whose founder had prior experience managing CF campaigns. He was appointed CEO of Gamma. The company's core business is centered on an innovative photovoltaic panel created and patented by two Bicocca University professors. The panel boasts the special feature of being entirely transparent, which strongly increases its power capacity and makes it possible for it to fully integrate with building facades.

In 2017, the first ECF campaign was launched on the Crowdfundme platform to obtain the financial resources needed in the business development phase. This campaign was a great success as the threshold was reached in less than one week. This generated huge interest in the company, which then took on a financial advisor to take all the steps - especially market and financial analysis - required by the emerging new business partnerships with potential investors. The real turning point occurred when one of the CF investors began endorsing the company through several highly qualified and profitable prospects, thus unveiling business opportunities that the company had not even imagined before:

He literally fell in love with our project and, incredibly, felt the need to put us in contact with all his best business partners (Gamma's CEO, interview).

This episode also provided the opportunity to better define the possible application fields for Gamma's technology and decide how to proceed with the next stages of the product development process.

In 2018, Gamma decided to start a new ECF campaign (Table 1), again on Crowdfundme, given the positive experience during the first $\mathrm{CF}$ project, hoping to once again reach a very high target threshold well ahead of the deadline. In this campaign, too, in addition to the financial resources obtained, the company was contacted by a member of one of the most powerful industrial families in Italy who firmly expressed the desire to become involved in the company's business development processes. Thanks to this last round of funding, the company was able to acquire the original product patents from the University and finally start manufacturing the first product series. The company had now become fully aware of the benefits of CF:

$\mathrm{CF}$ can generate so many opportunities. You really understand that only when you create a campaign. The comprehensive network you can join includes all the networks of your supporters. Of course, you get the money and money is vital for your company to take off, but along with that, you also get something that is at least as valuable as money. You welcome special partners who will offer you their skills, their energy and their networks. This really multiplies the value of your company (Gamma's CEO, interview).

Now, Gamma seems ready to enter a completely new phase in its growth path. In fact, it is on the verge of taking a new step forward, leaving CF for an initial coin offering and then, hopefully, a stock exchange listing.

\subsection{Delta case}

Delta's core business is portable 3D printers. In 2013, the first prototype was presented as a simple trial at an exhibition fair dedicated to inventors and creatives by a 3D technology specialist, Davide, and a marketing expert, Manuela, in a supporting role. To enhance the product, which had generated considerable interest, they decided to launch an NECF campaign (managed by Manuela) on Indiegogo with the specific objective of testing their product idea in an international competitive setting and:

[...] interact with knowledgeable people able to act as sort of co-developers [...] in an open project (Delta's marketing manager, interview).

The campaign results were an unexpected success, although the proponents soon realized that CF is not as easily managed as they had originally thought.

We needed to study to get prepared for such a challenge! Actually, we only had a rough idea of it (Delta's marketing manager, interview).

The CF campaign success gave them the opportunity to create a company in 2014, with the added support of a business incubator. The initial product prototype was developed further, evolving into a several different models, thanks to feedback from the backers, and successfully delivered.

From that point on, Davide and Manuela decided to systemically rely on NECF campaigns to improve the product and boost the business as it became clear that CF could be the perfect path for them to follow to access the market in an exploratory, co-evolutionary and innovative manner.

Through CF campaigns we could get in touch with users who did not really want a structured product; rather, they wanted a smart idea to work on with us and we had to be able to interact with them (Delta's marketing manager, interview).

In 2014, the second CF campaign was launched, again on Indiegogo (Table 1), specifically to enhance the product. Just one year later, a new item (a lighter weight 3D printer) was proposed to the backers through the third CF campaign on Kickstarter. In 2016, a new technology specialist and other part-time professionals joined Delta, and an agreement was signed with a multinational company for an important innovation project. These campaigns also enhanced Delta's direct sales as well as the brand's visibility and reputation, above all through the special collaboration with some of the backers who acted as opinion leaders in creative fields. They got involved in dedicated events and started to voluntarily endorse Delta on their social media channels.

In 2018, a new CF campaign was launched, again on Kickstarter, but this time it was a failure. Delta very soon 
realized that the item put up as a reward (i.e. a $3 \mathrm{D}$ professional viewer) was more suitable for a business-to-business context than for Kickstarter. Anyway, the start-up considers this episode an opportunity in marketing terms.

$\mathrm{CF}$ teaches you to always to be prepared to fix something in your product, in your working method, in your supply, even in your team! You always need to be flexible and responsive to find a new solution. That's a great way of enhancing your company in the long run! (Delta's marketing manager, netnography).

The company is currently about to launch a new special product, a self-assemble 3D printer, and it will highly likely be through a new NECF campaign.

\section{Findings}

The RQ is the focus of this section in which we follow our theoretical ARA framework. The participation of selected startups in CF campaigns will be analyzed in terms of actors, activities and resources.

\subsection{Actors}

With regard to actors, the selected cases highlight the recognition of $\mathrm{CF}$ as a viable source of funding by all entrepreneurs. CF is considered a possibility in the early stages (Wang et al., 2019), mainly as a channel for financial resources. Notwithstanding the limited knowledge of CF, company founders search for the most appropriate platform, trying to relate it to their main business or technical goals.

In the first CF campaign, proponents maintain a central role in the building of bonds with other actors (André et al., 2017). In this phase, our start-up firms found themselves in a completely new "playground" when facing the challenges - in terms of communication and interaction with potential backers - of the ongoing CF campaigns.

In the second CF campaign, a growing awareness of $\mathrm{CF}$ relevance and complexity by proponents seems to emerge, as they attempt to involve new partners in marketing activities. In various cases, a "hidden" role is played by technical managers and staff. On the one hand, the entrepreneur and/or the technical staff has been interacting with users and or experts on the product features and functions; on the other hand, a key role - in positive or negative terms - is played by those actors in charge of the production of prototypes, small lots of reward products or production planning to be discussed with backers and investors.

The cases highlight the possible impact of unexpected events that are related to the activism of key actors external or internal to the CF project and can affect the CF campaign. The CF effort by Alpha, for example, largely benefited from the sudden conflictual interaction with large firms such as PayPal and Google. In the case of Beta, the strong contribution by a single professional investor had a positive effect in terms of overall funding project reputation, overcoming the "wait and see" situation experienced in that phase of the first CF campaign. In both cases, the start-ups attempted to exploit to their advantage the emerging situations as they were unfolding.

The four cases show that different paths lead to the emergence of different types of partnering actors, who play a key role on both the CF campaign outcome and on the evolution of the start-up firm. Gamma and Delta show a more linear evolution given the homogeneity of the backers involved in their respective campaigns. Gamma was able to attract professionals, managers and firms as investors in both ECF campaigns, while single investors shaped the evolution of the CF campaign and the development process of the start-up. Delta discovered and then exploited in both campaigns the experimental nature of NECF, by promoting open interaction with innovative backers from a variety of backgrounds. In both cases, the start-ups were able to build on the backer networks activated in the first CF campaign. Alpha and Beta, instead, experienced significant changes in the mix of actors involved in the CF campaigns. Alpha dealt with regular consumers in the first NECF campaign and then faced the challenge of dealing with different kinds of backers (e.g. industrial firms, professionals, etc.) in the second campaign; this placed its strategy and capabilities under closer scrutiny. Beta chose the opposite path, building a strong base of investors in the first campaign (ECF) and then widening its overall business network in the second campaign (NECF).

In synthesis, participating in multiple CF campaigns widens the social and business network (Bessière et al., 2019) and also the mix of actors involved in managing and coordinating a $\mathrm{CF}$ campaign. In the extant literature on $\mathrm{CF}$ and serial $\mathrm{CF}$, the actors internal to the start-up have remained in the shadows. The present paper and the findings of this empirical analysis show that the start-up entrepreneurial team and the close network of supporting actors do play a relevant role in the multiple CF processes; they merit further attention in terms of analysis of the internal interaction processes involving both individual and organizational actors.

\subsection{Activities}

With regard to the activities implemented, all the companies show, to varying degree, the difficulties inherent to adapting to the complexity of CF campaigns in the first round (Brown et al., 2018; Xiang et al., 2019) and then, in the second round, following a more structured and conscious approach. Marketing activities, relationships with backers, management of product development and production activities are conducted on a contingency basis; this can cause various problems, which often become visible on the CF platform and on social media, with a resulting direct impact on the evolution of CF campaigns. All the cases in our study show that the startup firms attempted to improve the content and the coordination of activities in the second round of CF (Stanko and Henard, 2017).

In terms of platform selection, our case evidence shows that in the first round, the choice was based on limited searching and evaluation activities and, overall, it appears to have been more "passive" and shaped by the limited knowledge of the CF world and, therefore, by the liability of "newness" (Baraldi et al., 2019). In the second round, selection was more planned and took into account the first CF experience, the functioning of the various CF platforms, and the features of prospective targeted users/investors as backers on the platform. Overall, the second CF campaigns seem to suggest the emergence of a strategizing approach, showing a more "active engagement" (La Rocca et al., 2013), with key social and business networks to be tapped into through CF platforms.

With regard to marketing and communication activities, in three of the four cases the first CF campaign forced the start- 
ups to think about market and communication for the first time in a more integrated way. Introducing the main business/ product idea to an audience of potential backers meant having to use new marketing tools, such as videos and advertising on social media; this entailed a learning curve, as the functionality and impact of these tools on the CF campaign were not clear for most of the proponents, at the beginning. The complex experience in the first CF campaign motivated start-ups to devote increasing attention and resources to marketing activities to develop a network identity that was more attractive for backers and stakeholders (Laari-Salmela et al., 2019). Alpha and Gamma, both engaged in ECF campaigns in the second round, also devoted increased attention to market and financial analysis, which was to be shared with potential investors.

Another main setting for CF-related activities is the technical area of product and business development. The start-ups were developing the basic product idea before starting the CF project; later, during the CF campaigns, both entrepreneurs and technical staff were actively engaged in a technical dialogue with users/experts. These interactions were often visible to the CF community and they also had to do with the timing and features and new releases of the product or of parts of the product/prototype. This meant integrating technological development activities with the CF campaign. This interdependence of activities was "discovered" in the first round of CF and was more carefully managed and "exploited" in the second round.

Other key activities concern planning and management of production related tasks. Given the prominent role of tangible products/technologies in all the CF campaigns, the production of prototypes or small series has meant increasing complexity in the overall management of the CF campaign in progress and in the aftermath. In some cases, the main focus has been on the product development side, while the organization of production activities has not been considered a priority in the planning effort, leading to difficulties in terms of timing of product delivery (La Rocca et al., 2019).

These activities - related to marketing, product development and production management - have emerged mainly within the context of the CF campaign. Other new activities that progressively come into being have an impact on the management of CF campaigns. As mentioned above, participation in ECF campaigns has meant setting up and managing relationships with investors of different types, outside of the founding team. On the one hand, ECF is perceived as a channel for financial resources that does not require any significant involvement of investors. On the other hand, the community dimension of CF has pushed start-ups to devote time and effort to managing relationships with backers (Brown et al., 2019), during and after the ECF campaigns. This has represented a novelty for the start-ups' leading teams.

In sum, the empirical analysis clearly shows that the start-ups were pushed to engage in a wide variety of new activities substantially shaped by the specific nature and logics of $\mathrm{CF}$; for newly established start-up firms, this represents a setting that is difficult to control. The four start-ups had to face the newness of specific requirements for marketing, product development and production activities, for example, and of tight timing schedules influenced by the configuration of CF campaigns.

\subsection{Resources}

The cases show that participating in multiple CF campaigns allows the start-up teams to access various types of resources (Bessière et al., 2019; Stanko and Henard, 2017), notably in financial management, product development and marketing management (see Table 1).

Our analysis confirms that CF and multiple (or serial) CF allows for wider access to financial resources, often in combination with other sources of funding (Bruton et al., 2015; Roma et al., 2017). In some cases, it occurs in a contingent manner, while in other cases, successful CF represents a key factor in attracting key investors and the attention of the banking system. The start-up firms examined in this study were well aware of the different types of CF (Paschen, 2017) and tended to select the most appropriate option at various points along the process. This was apparent in the intermediate phase between the first and the second round of CF financing, when start-up firms linked their choice of the type of financing and the platform to their main strategic objectives.

All the cases show a positive impact, in terms of product development-related resources, when backers provide useful insights on the technical development of the product in various user settings. It seems clear that the ability to capture and exploit technical feedback from backers and users is linked to the development of marketing resources allowing firms to engage in fruitful interaction with the emerging CF community (Eldridge et al., 2021). It is apparent that in all the selected cases, participation in multiple CF campaigns fosters the development of resources in the marketing area. Start-up firms generally approach CF with limited marketing resources, in terms of both ad hoc organizational positions and knowledge. The nature, rules and logics of CF activities push them to activate new resources to fulfill the main CF requirements imposed by CF platforms. This, in turn, pushes the entrepreneurial team to start thinking in a more systematic way about the product and the target market, about communication goals and tools, and about key stakeholders and key social/ business networks. The upgrading of marketing resources is implemented in the following areas: organizational positions (internal/external), market knowledge, marketing management competences and skills and brand development. However, this upgrading process is not easily accomplished (Lagazio and Querci, 2018), as our empirical analysis underscores. The selected cases show that the start-up firms faced several difficulties because of their limited marketing competences at the beginning of the CF campaigns and the short time-period available for conducting the CF campaign.

It could be argued that access to and development of resources follows different pathways depending on what different combinations or series of ECF and NECF are opted for. For Gamma, two rounds of ECF consolidated their business model and widened their market horizon, helping the firm to start planning the next growth phase to be pursued. Delta's experience, instead, highlights the role of serial NECF for product development in an experimental context (Di Pietro et al., 2018) that links technical development with user involvement. The other two cases show hybrid features. Alpha undertook an incremental path as they went from NECF to $\mathrm{ECF}$, thus interacting with product users in the first round and then searching for additional financial resources to make the 
start-up organization more robust (Bessière et al., 2019; Eiteneyer et al., 2019) in the second. Beta did just the opposite, starting with ECF and then participating in an NECF campaign; in the first round, they searched for investors to secure initial resources for starting up the business and, then, in the second round, used NECF for explicit marketing goals.

To sum up, this research highlights that serial CF campaigns allow access to new resources in addition to financial ones, as acknowledged in the general literature on CF (Lehner et al., 2015; Viotto Da Cruz, 2018) but not emphasized in the literature on serial CF. This analysis underlines the complexity of the resource dimension: in multiple CF campaigns, the startups involved can improve the "assembly process" of resources (Ciabuschi et al., 2012), an aspect which should not be taken for granted as it is influenced by different contexts, whether production, development or end-user (Landqvist and Lind, 2019). As we saw in our case studies, product development was supported by marketing communication and this also meant that production resources were activated to fulfill the backers/ customers' requests. The empirical analysis shows that, during the first campaign, combinations of resources were characterized by frictions (Baraldi et al., 2012), while in the second campaign, integration was smoother, thanks to the learning processes that took place.

\section{Theoretical and managerial implications}

This paper provides three main theoretical contributions regarding the serial CF phenomenon. First, it underscores the usefulness of the ARA framework to gain a more articulated and exhaustive (Fehrer and Nenonen, 2020) analysis of the micro-processes of serial CF. In fact, compared to the existing studies on $\mathrm{CF}$ and serial $\mathrm{CF}$, this research highlights the role and evolution of internal actors (i.e. founders/entrepreneurs, staff, partners) as well as social and business networks (Brown et al., 2019); the interdependence and evolution of start-up business activities and CF-related activities; the role and evolution of key resources whose combination and integration might cause frictions (Baraldi et al., 2012) that impact CF campaigns. The ARA framework has been particularly helpful in unveiling a key component: activity (Arbin et al., 2018) somehow overlooked in the existing literature on serial $\mathrm{CF}$. Participation in multiple CF campaigns implies undertaking, over time, (often new) activities, such as marketing, product development and production planning, which are required and shaped by the specific logics of the CF platforms. CF's "rules of the game" represent a formalized "discipline" that pushes startup firms to engage in a variety of business and technical activities in a more structured way; the interdependence of these activities is shaped by the complexity of the content and the timing of the various CF campaigns, according to the specific typology of the chosen CF scheme. Therefore, startups participating in serial $\mathrm{CF}$ are increasingly engaged in specific activities related to coordination tasks, such as business networking (Ford and Mouzas, 2013) and assembly of resources (Ciabuschi et al., 2012). The emergence of these coordination activities allows start-ups to shift from an improvisational and contingent approach to a more carefully planned experimental behavior, to be pursed in subsequent CF campaigns or in other relevant business development contexts.
To sum up, the ARA framework shows that multiple CF campaigns are embedded in the overall ever-changing start-up network and are affected by parallel and overlapping start-up development processes. CF campaigns are not isolated projects and participation in multiple CF campaigns is always affected, to a certain extent, by the evolving configuration of actors (Brown et al., 2019), activities and resources connected to the specific context where the start-up itself is embedded. In this light, the present paper provides conceptual insights into the funding trajectory of start-ups, in line with recent studies (Bessière et al., 2019) and with the call for a management/ marketing perspective on the CF phenomenon (Brown et al., 2019; Fehrer and Nenonen, 2020).

As regards the second theoretical contribution, the adoption of the ARA model points out the need to rethink the "serial" dimension of multiple CF campaigns, which has often been overlooked or underexplored in the CF literature. Our research sheds light on how these processes can be more or less linear given that they can be affected by the type or combination of $\mathrm{CF}$ schemes chosen and by the degree of alignment of actors, activities and resources. The "assembly" (Ciabuschi et al., 2012) of the latter could be facilitated by emerging learning processes, but could also be impaired by unexpected circumstances, which are typical of the early stage development of start-up companies.

Finally, this paper expands the limited IMP research on start-ups and the financial setting, providing insights on the relevant phenomenon of CF and, notably, of serial CF. It could be argued that serial CF represents a valuable context where the collective nature of resource development in new businesses (Snehota, 2011; Ciabuschi et al., 2012) is displayed.

The findings of this research raise three main managerial implications. First, CF campaigns could represent a valuable option for accessing key resources in a more stable and systematic manner. Serial CF could be a source of additional stability on the financial side (Wang et al., 2019) and could be integrated within the overall strategy for accessing financial resources, which might include interaction with key players such as venture capital firms and financial institutions, increasingly oriented toward considering CF performance to conduct preliminary assessments of prospective investments in start-up firms.

Second, serial CF could represent a useful "playground" on the innovation side (Hu et al., 2015), as it allows for interaction with a variety of actors - both individual and business - that could have a role in shaping innovative solutions related to the product offering. However, this possibility is linked to the availability and use of appropriate marketing and production resources, which the nature of $\mathrm{CF}$ itself requires. Adequate real-time communication and timely production activities could reinforce relationships with backers and make them a key resource in the process of start-up firm development.

Third, facing these managerial challenges implies the development of critical capabilities for CF management (Fehrer and Nenonen, 2020). CF is a complex option (Lagazio and Querci, 2018; Lehner et al., 2015) requiring not only a clear understanding by the founders but also professional competences of collaborators/partners in charge of product development, production, and marketing activities. Assembly and coordination of activities and resources is a complex task in 
start-up firms (Ciabuschi et al, 2012), even more so in a CF setting. Participating in multiple CF campaigns entails cultivating an awareness of the possible synergies and interdependences between activities and resources activated in the first campaign and, then, using them to advantage in subsequent ones. Another key managerial aspect is related to the ability to engage in business networking (Fehrer and Nenonen, 2020; Nielsen, 2018), because selecting and managing the right $\mathrm{CF}$ partners requires skill, time and energy (Brown et al., 2018; Xiang et al., 2019) - resources that are often lacking in highly complex and challenging start-up settings.

\section{Limitations and future research directions}

This paper presents some limitations to be recognized. First, the empirical analysis focuses mainly on the first two rounds of $\mathrm{CF}$ and examines mostly successful campaigns. Implementing more than two CF campaigns could result in a variety of outcomes, leading to different paths; this means that CF might then play a different role in the start-up development process. In the case of failures, participation in serial CF campaigns could show different patterns that would then have an impact on the behavior of key actors and on the firm's access to needed resources. Second, the collection of data and the subsequent empirical analysis are mainly focused on start-up firms and less on a detailed reconstruction of the features of business and social networks. In this sense, this paper provides complementary insights to Brown et al. (2019) at the level of CF campaign proponents.

As regards future research, new avenues could further advance understanding and knowledge of serial CF by analyzing in more depth - using the ARA model or other conceptual tools - the various $\mathrm{CF}$ phases, i.e. pre-CF, active $\mathrm{CF}$ and post CF, building on Brown et al. (2019). In addition, within these phases, future studies could explore the main patterns of interaction between the CF proponent(s) and the CF platforms, which could play different roles and influence the degree of success of the CF campaigns. Finally, this empirical research confirms the relevance of the variety of financing options available in the different start-up phases (Brown et al., 2019; Paschen, 2017) in which firms choose to integrate financial resources from different channels in an uncertain business context. Additional studies are needed to gain a better understanding of serial $\mathrm{CF}$ within the funding trajectory (Bessière et al., 2019), especially pertaining to the possible synergies or frictions therein.

\section{References}

Aaboen, L., Dubois, A. and Lind, F. (2012), "Capturing processes in longitudinal multiple case studies", Industrial Marketing Management, Vol. 41 No. 2, pp. 235-246.

Aaboen, L., La Rocca, A., Lind, F., Perna, A. and Shih, T. (2017), "Starting up in business networks", Why Relationships Matter in Entrepreneurship, Palgrave McMillan, London.

André, K., Bureau, S., Gautier, A. and Rubel, O. (2017), "Beyond the opposition between altruism and Self-Interest: reciprocal giving in Reward-Based crowdfunding", fournal of Business Ethics, Vol. 146 No. 2, pp. 313-332.

Arbin, K., Kask, J. and Prenkert, F. (2018), "Is there a hierarchy among activities, resources, and actors in business networks? Exploring the relationship between the components of the ARA model", paper presented at the 34th IMP Conference, Marseille.

Baraldi, E., Gressetvold, E. and Harrison, D. (2012), "Resource interaction in Inter-Organizational networks: foundations, comparison, and a research agenda", fournal of Business Research, Vol. 65 No. 2, pp. 266-276.

Baraldi, E., Havenvid, I., M., Linné, Å. and Öberg, C. (2019), "Start-Ups and networks: interactive perspectives and a research agenda", Industrial Marketing Management, Vol. 80, pp. 58-67.

Barbi, M. and Mattioli, S. (2019), "Human Capital, investor trust, and equity crowdfunding", Research in International Business and Finance, Vol. 49, pp. 1-12.

Belleflamme, P., Lambert, T. and Schwienbacher, A. (2014), "Crowdfunding: tapping the right crowd", Fournal of Business Venturing, Vol. 29 No. 5, pp. 585-609.

Bessière, V., Stéphany, E. and Wirtz, P. (2019), "Crowdfunding, business angels, and venture capital: an exploratory study of the concept of the funding trajectory", Venture Capital, Vol. 22 No. 2, pp. 135-160.

Bocconcelli, R., Cioppi, M. and Pagano, A. (2017), "Social media as a resource in SMEs' sales process", fournal of Business E Industrial Marketing, Vol. 32 No. 5, pp. 693-709.

Brown, T.E., Boon, E. and Pitt, L.F. (2017), "Seeking funding in order to sell: crowdfunding as a marketing tool", Business Horizons, Vol. 60 No. 2, pp. 189-195.

Brown, R., Mawson, S. and Rowe, A. (2019), "Start-ups, entrepreneurial networks and equity crowdfunding: a processual perspective", Industrial Marketing Management, Vol. 80, pp. 115-125.

Brown, R., Mawson, S., Rowe, A. and Mason, C. (2018), "Working the crowd: improvisational entrepreneurship and equity crowdfunding in nascent entrepreneurial ventures", International Small Business fournal: Researching Entrepreneurship, Vol. 36 No. 2, pp. 169-193.

Bruton, G., Khavul, S. and Siegel, D. (2015), "New financial alternatives in seeding entrepreneurship: microfinance, crowdfunding, and Peer-To-Peer innovations", Entrepreneurship Theory and Practice, Vol. 39 No. 1, pp. 9-26.

Butticè, V., Colombo, M.G. and Wright, M. (2017), "Serial crowdfunding, social capital, and project success", Entrepreneurship Theory and Practice, Vol. 41 No. 2, pp. 183-207.

Cantù, C. (2018), "Discovering the collective entrepreneurial opportunities through spatial relationships", IMP fournal, Vol. 12 No. 2, pp. 276-295.

Cantù, C., Sepe, G. and Tzannis, A. (2018), "Exploring the role of business relationships in start-ups' life cycles evidences from the Italian context”, IMP fournal, Vol. 12 No. 3, pp. 519-543.

Ciabuschi, F., Perna, A. and Snehota, I. (2012), "Assembling resources when forming a new business", fournal of Business Research, Vol. 65 No. 2, pp. 220-229.

Di Pietro, F., Prencipe, A. and Majchrzak, A. (2018), "Crowd equity investors: an underutilized asset for open innovation 
in start-ups", California Management Review, Vol. 60 No. 2, pp. 1-28.

Dubois, A. and Gadde, L.-E. (2002), "Systematic combining: an abductive approach to case research", Fournal of Business Research, Vol. 55 No. 7, pp. 553-560.

Eisenhardt, K.M. (1989), "Making fast strategic decisions in high-velocity environments", Academy of Management fournal, Vol. 32 No. 3, pp. 543-576.

Eiteneyer, N., Bendig, D. and Brettel, M. (2019), "Social capital and the digital crowd: involving backers to promote new product innovativeness", Research Policy, Vol. 48 No. 8.

Eldridge, D., Nisar, T.M. and Torchia, M. (2021), "What impact does equity crowdfunding have on SME innovation and growth? An empirical study", Small Business Economics, Vol. 56 No. 1, pp. 105-120.

Fehrer, J.A. and Nenonen, S. (2020), "Crowdfunding networks: structure, dynamics and critical capabilities", Industrial Marketing Management, Vol. 88, pp. 449-464.

Ford, D. and Mouzas, S. (2013), "The theory and practice of business networking", Industrial Marketing Management, Vol. 42 No. 3, pp. 433-442.

Groza, M.P., Groza, M.D. and Barral, L.M. (2020), "Women backing women: the role of crowdfunding in empowering female consumer-investors and entrepreneurs", fournal of Business Research, Vol. 117, pp. 432-442.

Guercini, S. and Milanesi, M. (2019), "Newness and heritage in business networks: case analysis of university spin-offs", Industrial Marketing Management, Vol. 80, pp. 139-148.

Håkansson, H., Ford, D., Gadde, L.-E., Snehota, I. and Waluszewski, A. (2009), Business in Networks, Wiley, Chichester.

Håkansson, H. and Snehota, I. (1995), Developing Relationships in Business Networks, Routledge, London.

Håkansson, H. and Snehota, I. (2017), No Business is an Island: Making Sense of the Interactive Business World, Emerald Publishing Limited.

$\mathrm{Hu}, \mathrm{M} ., \mathrm{Li}, \mathrm{X}$. and Shi, M. (2015), "Product and pricing decisions in crowdfunding", Marketing Science, Vol. 34 No. 3, pp. 331-345.

Kaminski, J., Hopp, C. and Tykvová, T. (2019), "New technology assessment in entrepreneurial financing - does crowdfunding predict venture capital investments?", Technological Forecasting and Social Change, Vol. 139, pp. 287-302.

Kozinets, R.V. (2002), "The field behind the screen: using netnography for marketing research in online communities", Fournal of Marketing Research, Vol. 39 No. 1, pp. 61-72.

La Rocca, A., Ford, D. and Snehota, I. (2013), "Initial relationship development in new business ventures", Industrial Marketing Management, Vol. 42 No. 7, pp. 1025-1032.

La Rocca, A., Hoholm, T. and Mørk, B.E. (2017), "Practice theory and the study of interaction in business relationships: some methodological implications", Industrial Marketing Management, Vol. 60, pp. 187-195.

La Rocca, A., Perna, A., Snehota, I. and Ciabuschi, F. (2019), "The role of supplier relationships in the development of new business ventures", Industrial Marketing Management, Vol. 80, pp. 149-159.
Laari-Salmela, S., Mainela, T. and Puhakka, V. (2015), "Beyond network pictures: situational strategizing in network context", Industrial Marketing Management, Vol. 45, pp. 117-127.

Laari-Salmela, S., Mainela, T. and Puhakka, V. (2019), "Resolving the start-up identity crisis: strategizing in a network context", Industrial Marketing Management, Vol. 80, pp. 201-213.

Lagazio, C. and Querci, F. (2018), "Exploring the Multi-Sided nature of crowdfunding campaign success", fournal of Business Research, Vol. 90, pp. 318-324.

Landqvist, M. and Lind, F. (2019), "A start-up embedding in three business network settings - a matter of resource combining", Industrial Marketing Management, Vol. 80, pp. 160-171.

Lee, C.H. and Chiravuri, A. (2019), "Dealing with initial success versus failure in crowdfunding market: serial crowdfunding, changing strategies, and funding performance", Internet Research, Vol. 29 No. 5, pp. 1190-1212.

Lehner, O.M., Grabmann, E. and Ennsgraber, C. (2015), "Entrepreneurial implications of crowdfunding as alternative funding source for innovations", Venture Capital, Vol. 17 Nos 1/2, pp. 171-189.

Mamonov, S. and Malaga, R. (2019), "Success factors in title II equity crowdfunding in the United States", Venture Capital, Vol. 21 Nos 2/3, pp. 223-241.

Mollick, E. (2014), "The dynamics of crowdfunding: an exploratory study", fournal of Business Venturing, Vol. 29 No. 1, pp. 1-16.

Nielsen, K.R. (2018), "Crowdfunding through a partial organization lens - the co-dependent organization", European Management fournal, Vol. 36 No. 6, pp. 695-707.

Ordanini, A., Miceli, L., Pizzetti, M. and Parasuraman, A. (2011), "Crowdfunding: transforming customers into investors through innovative service platforms", fournal of Service Management, Vol. 22 No. 4, pp. 443-470.

Pagano, A., Petrucci, F. and Bocconcelli, R. (2018), "A business network perspective on unconventional entrepreneurship: a case from the cultural sector", Fournal of Business Research, Vol. 92, pp. 455-464.

Paschen, J. (2017), "Choose wisely: crowdfunding through the stages of the start-up life cycle", Business Horizons, Vol. 60 No. 2, pp. 179-188.

Patton, M.Q. (2001), Qualitative Research and Evaluation Methods, Sage Publications, Thousand Oaks, CA.

Petrucci, F. (2018), "The incubation process of mid-stage start-up companies: a business network perspective", IMP Fournal, Vol. 12 No. 3, pp. 544-566.

Pollack, J.M., Maula, M., Allison, T.H., Renko, M. and Günther, C.C. (2019), "Making a contribution to entrepreneurship research by studying Crowd-Funded entrepreneurial opportunities", Entrepreneurship Theory and Practice, pp. 1-16.

Quintens, L. and Matthyssens, P. (2010), "Involving the process dimensions of time in case based research", Industrial Marketing Management, Vol. 39 No. 1, pp. 91-99.

Raab, M., Schlauderer, S., Overhage, S. and Friedrich, T. (2020), "More than a feeling: investigating the contagious effect of facial emotional expressions on investment decisions in reward-based crowdfunding", Decision Support Systems, Vol. 135. 
Roma, P., Messeni Petruzzelli, A. and Perrone, G. (2017), "From the crowd to the market: the role of Reward-Based crowdfunding performance in attracting professional investors", Research Policy, Vol. 46 No. 9, pp. 1606-1628.

Skirnevskiy, V., Bendig, D. and Brettel, M. (2017), "The influence of internal social capital on serial creators' success in crowdfunding", Entrepreneurship Theory and Practice, Vol. 41 No. 2, pp. 209-236.

Snehota, I. (2011), "New business formation in business networks", IMP fournal, Vol. 5 No. 1, pp. 1-9.

Stanko, M.A. and Henard, D.H. (2016), "How crowdfunding influences innovation", MIT Sloan Management Review, Vol. 57 No. 3, pp. 15-17.

Stanko, M.A. and Henard, D.H. (2017), "Toward a better understanding of crowdfunding, openness and the consequences for innovation", Research Policy, Vol. 46 No. 4, pp. 784-798.

Viotto Da Cruz, J. (2018), "Beyond financing: crowdfunding as an informational mechanism", fournal of Business Venturing, Vol. 33 No. 3, pp. 371-393.

Wang, W., Mahmood, A., Sismeiro, C. and Vulkan, N. (2019), "The evolution of equity crowdfunding: insights from
Co-Investments of angels and the crowd", Research Policy, Vol. 48 No. 8.

Xiang, D., Zhang, L., Tao, Q., Wang, Y. and Ma, S. (2019), "Informational or emotional appeals in crowdfunding message strategy: an empirical investigation of backers' support decisions", fournal of the Academy of Marketing Science, Vol. 47 No. 6, pp. 1046-1063.

Yin, R.K. (2003), Case Study Research: Design and Methods, Sage, Thousand Oaks, CA.

Yin, R.K. (2011), Applications of Case Study Research, Sage, Thousand Oaks, CA.

\section{Further reading}

Mattila, M. (2017), "Coping with friction during technology commercialization", IMP fournal, Vol. 11 No. 2, pp. 251-273.

\section{Corresponding author}

Roberta Bocconcelli can be contacted at: roberta. bocconcelli@uniurb.it 